Article

\title{
Experimental Investigation on the Fatigue Life of Ti-6Al-4V Treated by Vibratory Stress Relief
}

\author{
Han-Jun Gao ${ }^{1}$, Yi-Du Zhang ${ }^{1}$, Qiong $W^{1}{ }^{1, *}$ and Jing Song ${ }^{2}$ \\ 1 State Key Laboratory of Virtual Reality Technology and Systems, \\ School of Mechanical Engineering and Automation, Beijing University of Aeronautics and Astronautics, \\ Beijing 100191, China; gao.hanjun@buaa.edu.cn (H.-J.G.); ydzhang@buaa.edu.cn (Y.-D.Z.) \\ 2 Beijing Institute of Aerospace Systems Engineering, Beijing 100076, China; songjing@buaa.edu.cn \\ * Correspondence: wuqiong@buaa.edu.cn; Tel.: +86-10-8231-7756
}

Academic Editor: Filippo Berto

Received: 1 April 2017; Accepted: 28 April 2017; Published: 3 May 2017

\begin{abstract}
Vibratory stress relief (VSR) is a highly efficient and low-energy consumption method to relieve and homogenize residual stresses in materials. Thus, the effect of VSR on the fatigue life should be determined. Standard fatigue specimens are fabricated to investigate the fatigue life of Ti-6Al-4V titanium alloy treated by VSR. The dynamic stresses generated under different VSR amplitudes are measured, and then the relationship between the dynamic stress and vibration amplitude is obtained. Different specimen groups are subjected to VSRs with different amplitudes and annealing treatment with typical process parameters. Residual stresses are measured to evaluate the stress relieving effects. Finally, the fatigue behavior under different states is determined by uniaxial tension-compression fatigue experiments. Results show that VSR and annealing treatment have negative effects on the fatigue life of Ti-6Al-4V. The fatigue life is decreased with the increase in VSR amplitude. When the VSR amplitude is less than $0.1 \mathrm{~mm}$, the decrease in fatigue limit is less than $2 \%$. Compared with specimens without VSR or annealing treatment, the fatigue limit of the specimens treated by VSR with $0.2 \mathrm{~mm}$ amplitude and annealing treatment decreases by $10.60 \%$ and $8.52 \%$, respectively. Although the stress relieving effect is better, high amplitude VSR will lead to the decrease of Ti-6Al-4V fatigue life due to the defects generated during vibration. Low amplitude VSR can effectively relieve the stress with little decrease in fatigue life.
\end{abstract}

Keywords: fatigue life; vibratory stress relief; titanium alloy Ti-6Al-4V; residual stress; annealing treatment

\section{Introduction}

Residual stresses exist in many fabricated structures due to plastic deformation from thermal and mechanical operations during manufacturing [1]. The presence of residual stresses in engineering components and structures significantly affect the fatigue behavior [2], strength [3], and dimensional stability [4]. Many studies have been conducted to investigate the effects of residual stress on the fatigue life of different materials [5-7]. The effects of residual stress and surface hardness on the fatigue life under different cutting conditions of $0.45 \% \mathrm{C}$ steel were studied by Sasahara [8]. Their experimental results show that the fatigue life of machined components can be increased if compressive residual stress and high hardness within surface layer can be induced by a cutting process. Fatigue crack growth from a hole with a pre-existing compressive residual stress was simulated utilizing the 2D elastic-plastic finite element (FE) model by LaRue and Daniewic [9]. Pouget and Reynolds [10] determined that fatigue crack propagation in friction stir-welded AA2050 was strongly linked with the presence of residual stresses, and compressive residual stresses in the heat affected zone were responsible for the apparent improvement of fatigue behavior when the crack approached the weld. 
Surface compressive stress can inhibit the initiation and propagation of fatigue cracks. Some processes, such as rolling, laser peening and shot peening, are utilized to improve the fatigue life by inducing surface compressive residual stress. The effect of different shot peening treatments on the reverse bending fatigue behavior of 7075-T651 aluminum alloy was investigated by Benedetti et al. [11]. They demonstrated that controlled shot peening that employed ceramic beads determined a remarkable increment of the high-cycle fatigue resistance, which ranges between $15 \%$ and $50 \%$. Nikitin et al. [12] found that laser shock peening produced similar amounts of lifetime enhancements as deep rolling. The cycle, stress amplitude and temperature-dependent relaxation of compressive residual stresses was more pronounced than the decrease of near-surface work hardening. Bagherifard et al. [13] concluded that severe shot peening induced near surface grain refinement to nano and sub-micron range and transformed the austenite phase into strain-induced $\alpha^{\prime}$-martensite in a layered deformation band structure. The effect of small defects on fatigue threshold of different series of nitride and nitride-shot peened low alloy steel specimens was investigated by Fernández-Pariente et al. [14] through experiments.

Some researchers show interest in the fatigue behavior of Ti-6Al-4V. Zabeen et al. [15] evaluated the changing tendency of the Ti-6Al-4V titanium alloy residual stress field with fatigue crack growth after laser shock peening. Yamashita et al. [16] investigated the method of estimating the fatigue strength of small notched Ti-6Al-4V specimen using the theory of critical distance that employed the stress distribution in the vicinity of the notch root. Bourassa et al. [17] explored surface thermal/mechanical processing of Ti-6Al-4V to improve the fatigue strength of microknurled specimens via the production of a Ti-6Al-4V dual microstructure. Golden et al. [18] investigated the fatigue variability of an alpha + beta processed Ti-6Al-4V turbine engine alloy by conducting a statistically significant number of repeated tests at a few conditions.

The stress relieving process is generally conducted to improve the fatigue life and dimensional accuracy [19]. Natural stress relief, thermal stress relief (TSR), and vibratory stress relief (VSR) [20] are the most common methods. VSR is a general term used to refer to the reduction of residual stress by means of cyclic loading treatments. When the superposition of the dynamic stress and initial residual stress reaches the elastic limit of the material, plastic deformations occur in local positions, which leads to the residual stress release. Low cyclic stress amplitude can also release the stress after enough cycle times due to the generation of dislocation slip and multiplication at the micro level [21]. As a highly efficient and low-energy consumption method, VSR has received much attention from scholars and engineers in recent years. Sun et al. [22] concluded that the tensile properties of a marine shafting of 35\# bar steel bar changed slightly before and after vibration, whereas the macro residual stress decreased notably by approximately $48 \%$. Results in literature [23] show that the macro-residual stresses of the welded steel plates of D6AC and D406A decreased to $0 \pm 25 \mathrm{MPa}$ after VSR. Wang et al. [24] believed that the relaxation effect of compressive residual stress after VSR was better than that of tensile residual stress; the compressive residual stress and texture density increased first and then decreased with an increase in the vibration time. The said researchers also determined in another study that the strong basal textures of AZ31 Mg alloys would be weaken when the vibration time was more than $10 \mathrm{~min}$ [25].

Moreover, a residual stress decrease model of 304L under cyclic loading was established by Rao et al. [26] to evaluate the VSR effectiveness. Kwofie [27] proposed a theoretical plasticity model to study the residual stress relief mechanism under mechanical vibration. A combined method of TSR and VSR (TVSR) to extend the VSR effects was proposed by Lv and Zhang [28]. Their experimental results show that the maximum stress of the 7075 aluminum alloy plate decreased by $55.9 \%$ and $13.4 \%$ after TVSR and VSR, respectively. A mathematical model based on plasticity theorem with linear kinematic hardening was presented by Vardanjani et al. [29] to explain the reduction mechanism of residual stresses caused by VSR.

Nowadays, researchers have divergent opinions about the VSR effects on the fatigue life. Several of them believe that VSR can decrease the fatigue life, but others hold the opposite view. Djuric et al. [30] evaluated the fractal dimension of welded high-strength martensitic steel utilizing Barkhausen Noise 
Analysis and observed an increase in the fatigue damage to the microstructure due to the applied VSR treatment. This study indicates that VSR can have a negative effect on the fatigue life. Wozney and Crawmer [31] indicated that stress reduction did not occur uniformly throughout vibrated structures, and the possibility of fatigue damage during VSR treatment couldn't be neglected. On the contrary, the VSR and TSR effects on the fatigue lives of welded specimens made of $0.18 \%$ carbon steel were investigated by Munsi et al. [32]. Their experimental results show that the fatigue lives of the specimens treated by TSR decreased by $43 \%$, whereas those treated by VSR increased by $17 \%$. Song and Zhang [33] determined that vibratory stress relief could improve the fatigue life of 7075-T651 aluminum alloy when the dynamic stress was less than $8 \%$ of the yield limit.

Therefore, the VSR effect on the fatigue life is still ambiguous. VSR can have different effects on the fatigue life of different materials. The present study manufactures a batch of standard fatigue specimens to investigate the fatigue life of Ti-6Al-4V titanium alloy treated by VSR. Dynamic stresses generated under different VSR amplitudes are initially measured, and then the relationship between dynamic stress and vibration amplitude is obtained. VSRs with $0.03,0.05,0.1$, and $0.2 \mathrm{~mm}$ amplitude and annealing treatment with typical process parameters are then conducted on five specimen groups. Another specimen group without any treatment is employed for comparison. The residual stresses of each group are subsequently measured to study the stress relieving effect. Finally, the fatigue limits and cyclic stress amplitude-logarithm of cycle numbers $(\mathrm{S}-\operatorname{lgN})$ curves under different states are obtained by uniaxial tension-compression fatigue experiments.

\section{Experiments}

Standard fatigue specimens are manufactured from $\phi 30 \mathrm{~mm} \times 200 \mathrm{~mm}$ (diameter $\times$ length) extrusion Ti-6Al-4V titanium alloy bars. The specimen shape and size (Figure 1) are determined based on the China National Standard GB/T 3075-2008. Threads on both ends are utilized for clamping in the experiments.

A cylindrical counterweight with $40 \mathrm{~mm}$ diameter and $30 \mathrm{~mm}$ length, which is also made of Ti-6Al-4V titanium alloy, is added to one end of the specimen to lower the natural frequency and increase the dynamic stress (Figure 2a). The counterweight is fixed to the specimen by a thread in the dynamic stress measurement and VSR tests.
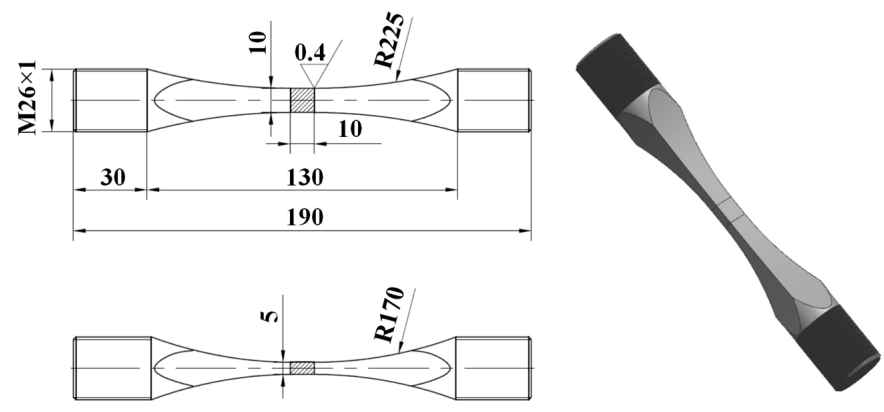

Figure 1. Ti-6Al-4V titanium alloy fatigue specimen.

\subsection{Dynamic Stress Measurement Tests}

Dynamic stress, which is the key factor that affects the stress relieving effect and fatigue life, is generated in the specimen during the VSR process. The dynamic stress magnitude can be controlled by changing the vibration magnitude. Therefore, dynamic stress measurement tests are conducted to obtain the relationship between the vibration magnitude and generated dynamic stress before the VSR tests.

A modal analysis is performed to calculate the vibration modes utilizing ANSYS Finite Element Analysis (FEA) software [34,35], as well as determine the strain measuring point and exciting frequency in the dynamic stress measurement and VSR tests. The FEA modal analysis steps are described as 
follows: (1) a 3D geometry model is imported; (2) the element type is selected as Solid 185; (3) the material properties are defined as shown in Table 1, which is provided by the manufacturer (Hangzhou Hengchao Metallic Materials Co., Ltd., Hangzhou, China); (4) the FE model is built (Figure 2a); (5) the boundary conditions are defined; (6) a solution is generated; and (7) the results are outputted.

Table 1. Mechanical properties of the Ti-6Al-4V titanium alloy.

\begin{tabular}{cccc}
\hline Density $/ \mathbf{k g} \cdot \mathbf{m}^{\mathbf{3}}$ & Elastic Modulus/GPa & Poisson's Ratio & Yield Strength/MPa \\
\hline 4440 & 110 & 0.33 & 980 \\
\hline
\end{tabular}

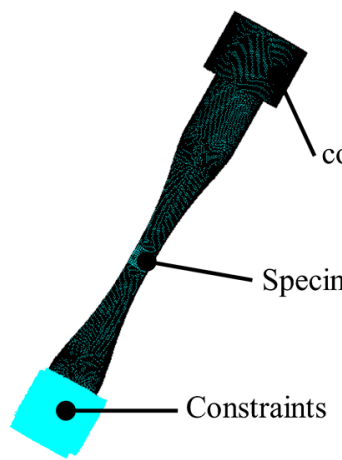

FE model

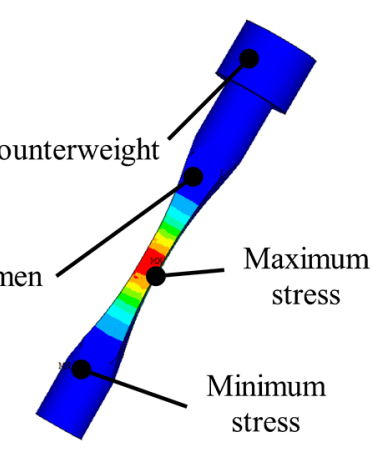

Stress results of $1_{\text {st }}$ order vibration mode

(a)

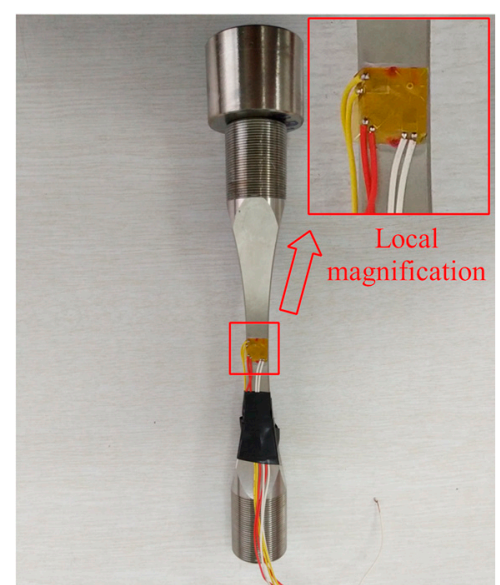

(b)

Figure 2. Finite element (FE) modal analysis and sticking position of the strain rosette: (a) FE model and first-order vibration mode result; and (b) sticking position of the strain rosette.

Simulation results show that the natural frequency of the first vibration mode is $52.07 \mathrm{~Hz}$, and the maximum stress occurs in the middle of the specimen (Figure 2a). Thus, a strain rosette that consists of $0^{\circ}$ (axial direction of the specimen), $45^{\circ}$, and $90^{\circ}$ (perpendicular to the axial direction of the specimen) direction strain gauges is attached onto the middle of the specimen (Figure $2 b$ ).

A V8-440 HBT 900C vibration table (LDS Test and Measurement Ltd., Royston, England) is employed as the excitation equipment, and the dynamic strain gauge and digital signal-processing system produced by China Orient Institute of Noise \& Vibration are utilized for the dynamic strain measurement and signal acquisition. The experimental setup is shown in Figure 3.

One end of the specimen without the counterweight is fixed to the vibration table, whereas the other end with a counterweight is free. The exciting frequency is set at $52 \mathrm{~Hz}$ according to the FEM simulation results. A total of 20 experimental sets are performed with 20 different vibration amplitudes. The vibration amplitudes (peak-to-peak value) range from $0.01 \mathrm{~mm}$ to $0.2 \mathrm{~mm}$. The vibration direction is parallel to the normal direction of the strain rosette plane and perpendicular to the direction of the specimen's axial direction.

The vibration time at each amplitude is $1 \mathrm{~min}$, and the effective values of dynamic strains at the $0^{\circ}, 45^{\circ}$, and $90^{\circ}$ directions can be read from the digital signal-processing system. Dynamic stresses can then be calculated utilizing Equations (1)-(3) [36]:

$$
\begin{aligned}
& \sigma_{1}=\frac{E}{2(1-\mu)}\left(\varepsilon_{a}+\varepsilon_{c}\right)+\frac{E}{\sqrt{2}(1+\mu)} \sqrt{\left(\varepsilon_{a}-\varepsilon_{b}\right)^{2}+\left(\varepsilon_{b}-\varepsilon_{c}\right)^{2}}, \\
& \sigma_{2}=\frac{E}{2(1-\mu)}\left(\varepsilon_{a}+\varepsilon_{c}\right)-\frac{E}{\sqrt{2}(1+\mu)} \sqrt{\left(\varepsilon_{a}-\varepsilon_{b}\right)^{2}+\left(\varepsilon_{b}-\varepsilon_{c}\right)^{2}},
\end{aligned}
$$




$$
\sigma_{\text {eqv }}=\sqrt{\frac{1}{2}\left[\left(\sigma_{1}-\sigma_{2}\right)^{2}+\left(\sigma_{2}-\sigma_{3}\right)^{2}+\left(\sigma_{3}-\sigma_{1}\right)^{2}\right]},
$$

where $\varepsilon_{a}, \varepsilon_{b}$, and $\varepsilon_{c}$ are the measured strains at the $0^{\circ}, 45^{\circ}$, and $90^{\circ}$ directions, respectively; $\sigma_{1}, \sigma_{2}$, and $\sigma_{3}$ are the first, second, and third principal stresses, respectively ( $\sigma_{3}$ is zero in the plane problems); $\sigma_{\text {eqv }}$ is the equivalent stress (von Mises stress); $E$ is the elastic modulus; and $\mu$ is Poisson's ratio. Thus, the generated dynamic stresses under different amplitudes can be obtained.

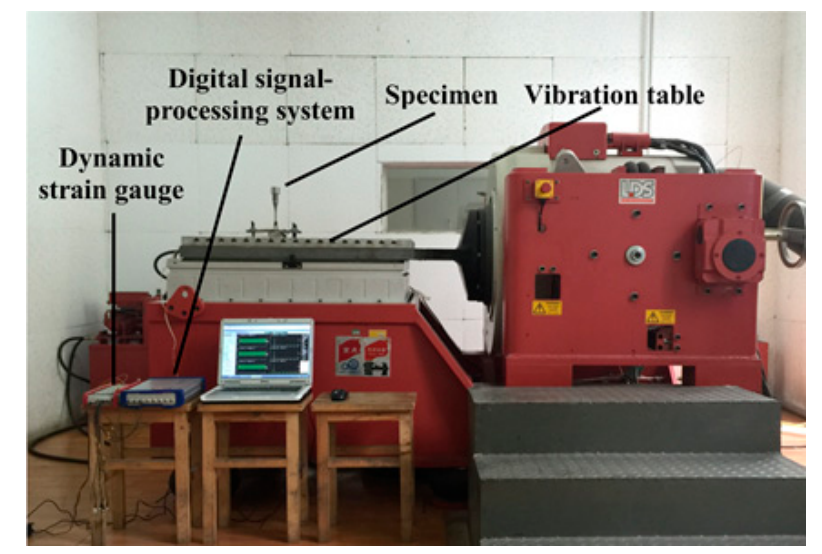

Figure 3. Dynamic stress measurement and vibratory stress relief (VSR) test setup.

\subsection{VSR Tests}

VSR tests are performed utilizing the same vibration table and fixture as the dynamic stress measurement tests. A total of 240 specimens are evenly divided into six groups (Figure 4). The specimens in Group A are in their original state without VSR or heat treatment. Four typical vibration amplitudes, which correspond to four typical dynamic stress levels, are selected based on the dynamic stress measurement test results. Thus, VSRs with $0.03,0.05,0.1$, and $0.2 \mathrm{~mm}$ vibration amplitudes are performed on the specimens in Groups B, C, D, and E, respectively. The vibration time for each specimen is $10 \mathrm{~min}$.

Moreover, annealing treatment is conducted on the specimens in Group F for comparison. The specimens are placed in a WZH-60 vacuum heat treatment furnace (produced by Beijing Research Institute of Mechanical \& Electrical Technology, Beijing, China) and heated to $600{ }^{\circ} \mathrm{C}$. The temperature is maintained at $600{ }^{\circ} \mathrm{C}$ for $6 \mathrm{~h}$ [37]. The specimens are then removed from the furnace and cooled to room temperature in open air.

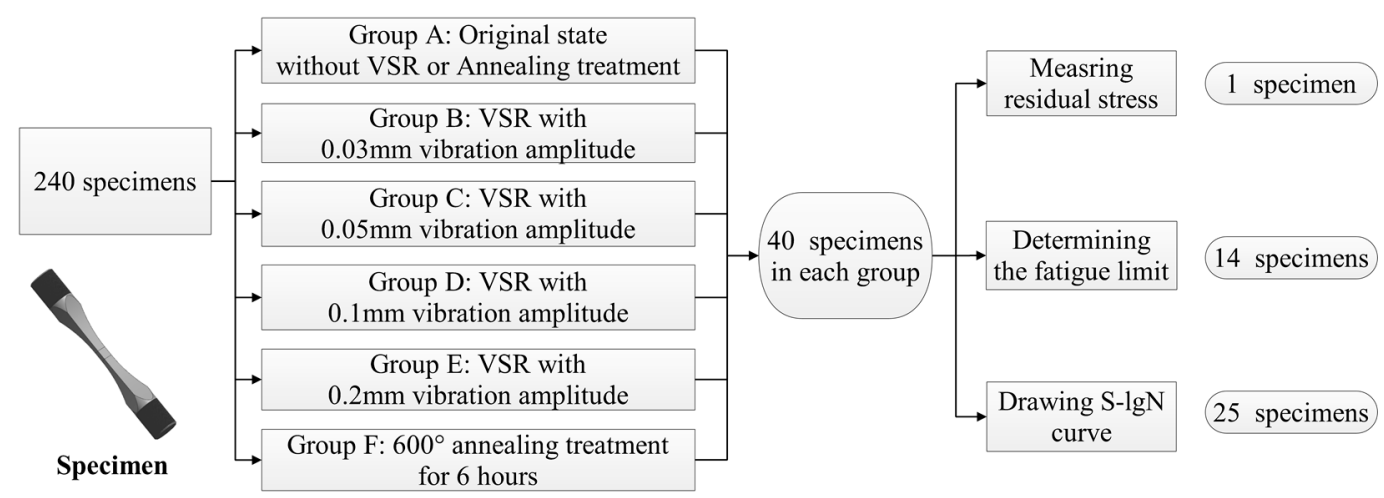

Figure 4. Grouping conditions of the vibratory stress relief(VSR) tests. 


\subsection{Residual Stress Measurement Tests}

One of the 40 specimens in each group is selected for the residual stress measurement tests after VSR and annealing treatment. In particular, the measured stresses of the specimens in Group A reflect the original stresses without VSR or annealing treatment. Hence, the stresses before and after VSR and annealing treatment can be obtained.

The Prism System (produced by Stresstech Group, Vaajakoski, Finland, which is a residual stress measurement device based on the hole-drilling method and electronic speckle pattern interferometry technique, and a $\phi 1.6 \mathrm{~mm}$ cemented carbide micro-milling cutter with titanium nitride coating (Richards Micro-Tool, Inc., Plymouth, MA, USA) are employed for the residual stress measurement (Figure 5). The measuring point is the same as the position where the strain rosette is attached (Figure 2b) in the dynamic stress measurement tests. A small hole with $1.6 \mathrm{~mm}$ diameter and $1 \mathrm{~mm}$ depth is drilled on the specimen by the micro-milling cutter. Hence, the stresses from the surface to $1 \mathrm{~mm}$ depth at the measuring point can be obtained.

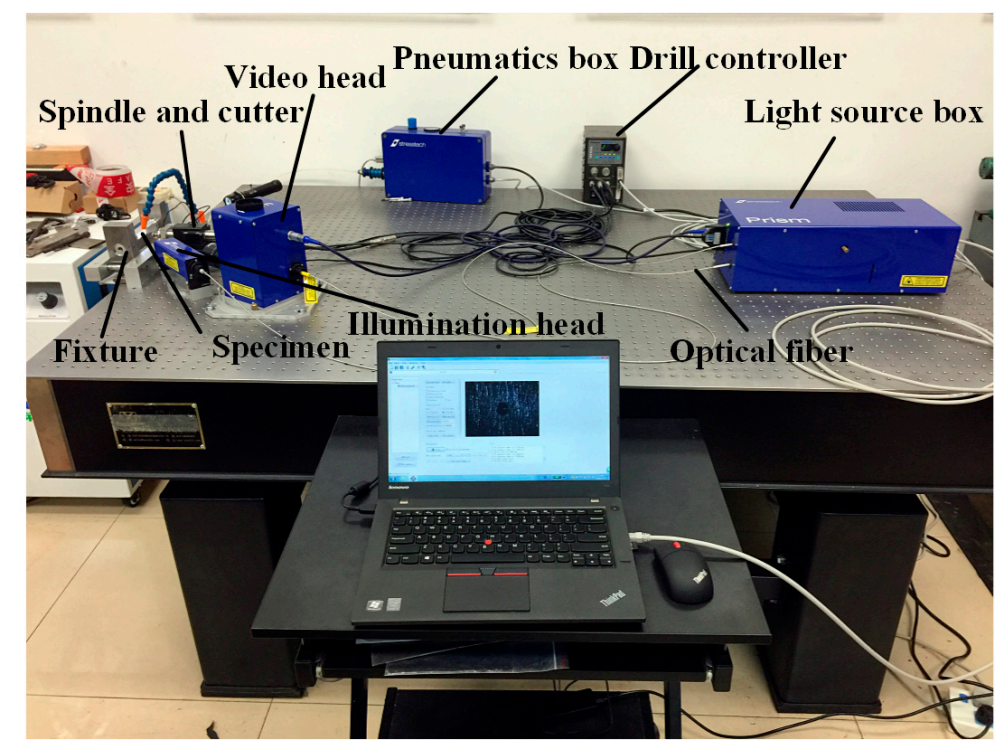

Figure 5. Setup of the residual stress measurement tests.

\subsection{Uniaxial Tension-Compression Fatigue Experiments}

The high-frequency fatigue testing machine QBG 200 (Changchun Qianbang Test Equipment Co., Ltd., Changchun, China) is adopted to perform the uniaxial tension-compression fatigue experiments (Figure 6). The stress ratio $R$ is -1 , and the load frequency is set at $81.7 \mathrm{~Hz}$ with a $5 \mathrm{~Hz}$ drop protection. The alternating and average load protections are both set at $\pm 5 \mathrm{KN}$, ambient temperature is $25^{\circ} \mathrm{C}$, and relative humidity is $39.2 \%$.

A total of 14 specimens from each group are selected to determine the fatigue limit. The up and down method [38] is applied, whose procedure is described in Figure 7. The cyclic stress amplitude of the first specimen for Group A is set at $520 \mathrm{MPa}$, which is slightly higher than half of the titanium alloy yield limit (490 MPa). The measured fatigue limit of Group A (original state) indicates that the cyclic stress amplitude of the first specimen for Groups B, C, D, E, and F are set at 500, 500, 490, 450, and $470 \mathrm{MPa}$, respectively. 


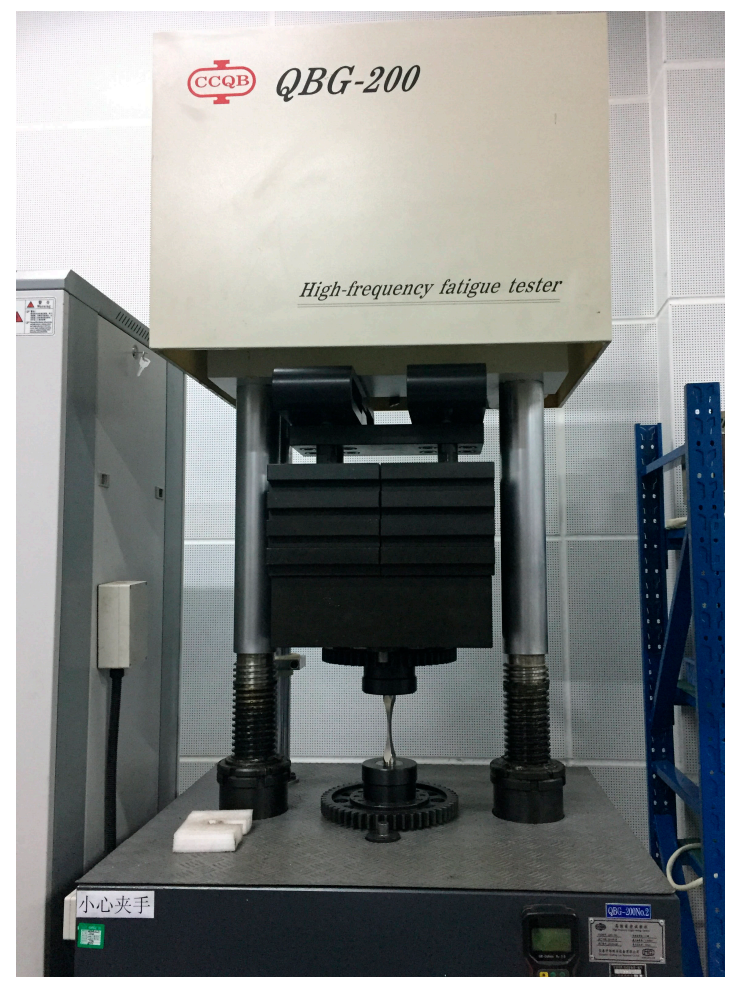

Figure 6. Setup of the fatigue experiments.

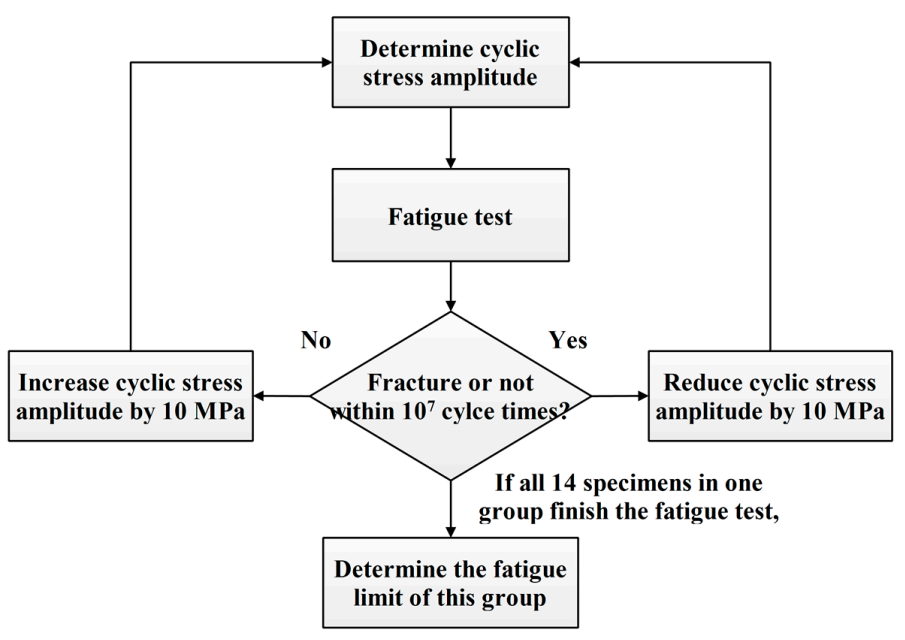

Figure 7. Procedure of the up and down method.

Fracture commonly occurs to the first specimen due to the high cyclic stress amplitude. No fracture occurs to one specimen within $10^{7}$ cycle times for the first time with the decrease in the cyclic stress amplitude. The first appearance of the no-fractured specimen and its previous fractured specimen are considered as effective specimens. If two specimens have the opposite fracture results (i.e., one is fractured, whereas the other is unfractured) and adjacent cyclic stress amplitude ( $\pm 10 \mathrm{MPa})$, then both are regarded as effective specimens. The fatigue limit can then be calculated by Equation (4):

$$
\sigma_{R=-1}=\frac{1}{m} \sum_{i=1}^{n} v_{i} \sigma_{i}
$$


where $m$ is the total number of effective specimens; $n$ is the number of cyclic stress amplitudes; $\sigma_{i}$ is the $i$ th cyclic stress amplitude; and $v_{\mathrm{i}}$ is the number of specimens at $\sigma_{i}$ cyclic stress amplitude.

After the fatigue limit is determined, $25(5 \times 5)$ of the 40 specimens in each group are selected to obtain the S-lgN curve with the grouping method [38]. Five cyclic stress amplitudes of each group are selected based on the fatigue limit. The fatigue cycles of 5 specimens under each cyclic stress amplitude are measured. Chauvenet's criterion [39] is employed to filter the experimental data and calculate the average fatigue cycle under each stress amplitude. Thus, the S-lgN curve of each group can be drawn.

\section{Results and Discussion}

\subsection{Dynamic Stress Measurement Tests}

The dynamic stress measurement test results are shown in Figure 8a,b. The first principal, second principal, and equivalent stresses under different amplitudes are calculated using Equations (1)-(3). This study utilizes the equivalent stress to reflect the dynamic stress magnitude. Figure $8 \mathrm{~b}$ shows that the equivalent stress generated in the VSR can be expressed by VSR amplitude (denoted by A) utilizing the linear fitting method in Equation (5):

$$
\sigma_{\text {eqv }}=404.33 \cdot A+0.18
$$

The dynamic stress increases linearly with the amplitude increase. The generated dynamic stresses under $0.03,0.05,0.1$, and $0.2 \mathrm{~mm}$ amplitude VSRs are $8.68,14.43,28.76$, and $57.22 \mathrm{MPa}$, respectively.

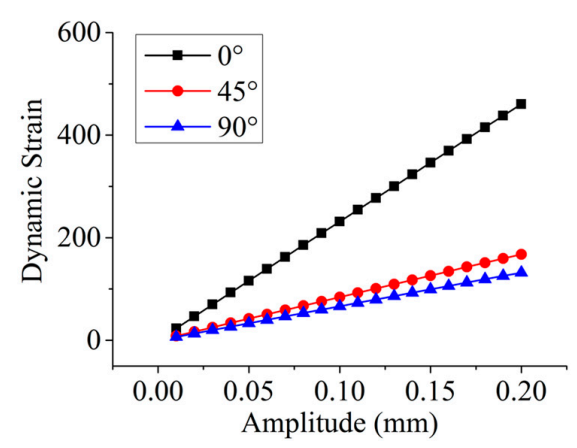

(a)

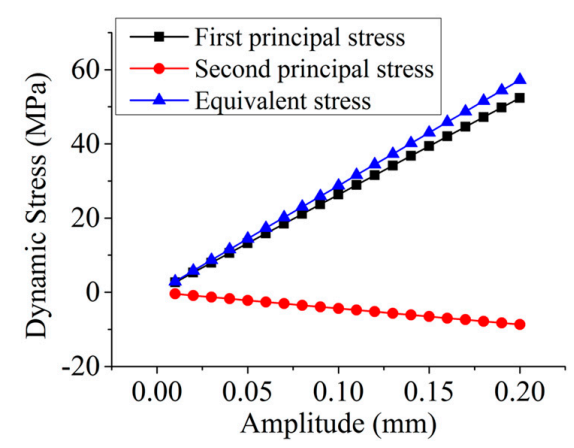

(b)

Figure 8. Dynamic stress and strain under different amplitudes: (a) dynamic strain; and (b) dynamic stress.

\subsection{Residual Stress Measurement Tests}

Plane stresses, including normal stresses in two mutually perpendicular directions and shear stress, are measured in the residual stress measurement tests. The first principal stress is calculated to compare the residual stress change before and after VSR or annealing treatment. The residual stresses of Groups A to F are shown in Figure 9a,b.

Figure 9a shows that the magnitude of the first principal stress on the surface layer $(0.02 \mathrm{~mm}-0.1 \mathrm{~mm}$ depth) of each group is much larger than those in the deeper layer $(0.1 \mathrm{~mm}-1 \mathrm{~mm})$ because of the machining-induced residual stress [40,41]. The peak and average stresses of Group A are significantly larger than those of Groups B to F. This scenario indicates that VSR and annealing treatment largely contribute to the stress relief and homogenization of Ti-6Al-4V titanium alloy. Comparing the results of Groups B to E shows that the stress magnitude decreased when the VSR amplitude increased. Therefore, a higher amplitude that generates a higher dynamic stress during VSR is more conducive to the relief and homogenization of the residual stress than the lower amplitude. 


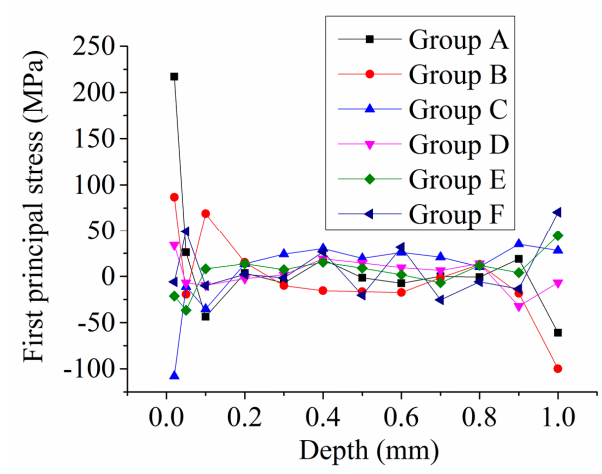

(a)

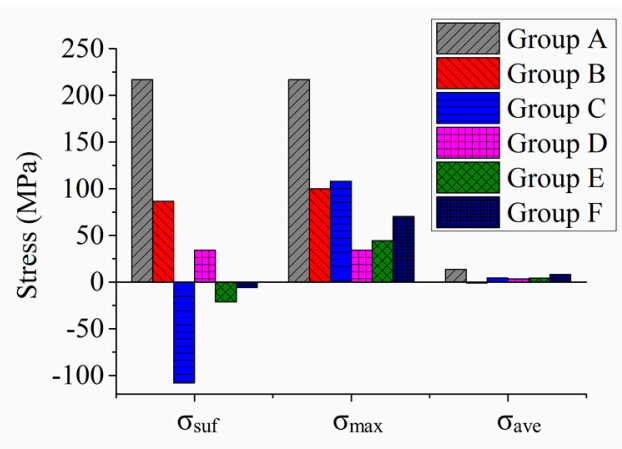

(b)

Figure 9. Measured stresses of Groups A to F after the VSR tests: (a) first principal stresses along the depth direction; and (b) comparison of the measured stress among the different groups (i.e., $\sigma_{\text {surf }}, \sigma_{\max }$, and $\sigma_{\text {ave }}$ denote the stresses at $0.02 \mathrm{~mm}$ depth, absolute value of the peak stress, and average stress along the depth direction, respectively).

\subsection{Uniaxial Tension-Compression Fatigue Experiments}

The fatigue limits of the specimens in Groups A to F are shown in Figure 10, whereas the S-lgN curves of Groups A to F are shown in Figure 11. The fatigue limit, surface residual stress, average stress, and dynamic stress of each group are compared in Table 2. Figures 10 and 11, as well as Table 2, show that the fatigue limits of Groups B to F are smaller than that of Group A. The fatigue limit decreased with the increase in the VSR vibration amplitude. The fatigue limit of Group F is smaller than those of Groups B, C, and D, but slightly larger than that of Group E. The S-lgN curve also decreased with the vibration amplitude increase. The S-lgN curve of Group F is generally lower than those of Groups B to E.

The fatigue life of Ti-6Al-4V titanium alloy decreased with the increase in the VSR vibration amplitude. Although the fatigue limit of Ti-6Al-4V titanium alloy decreased by $1.25 \%, 1.25 \%$, and $1.87 \%$ after $0.03,0.05$, and $0.1 \mathrm{~mm}$ amplitude VSR, the surface residual stress (at $0.02 \mathrm{~mm}$ depth) decreased by $60.05 \%, 50.23 \%$, and $84.29 \%$, respectively. The average residual stress within $1 \mathrm{~mm}$ depth also decreased by $90.99 \%, 67.02 \%$, and $74.68 \%$, respectively. When the amplitude reaches $0.2 \mathrm{~mm}$, the fatigue limit decreased by $10.06 \%$, the surface stress decreased by $90.18 \%$, and the average stress decreased by $68.68 \%$. The fatigue limit after the annealing treatment decreased by $8.52 \%$, the surface stress decreased by $97.28 \%$, and the average stress decreased by $39.87 \%$. These results indicate that low-amplitude VSR can significantly lower and homogenize the residual stress of Ti-6Al-4V titanium alloy with an extremely low cost to the fatigue life. By contrast, the high-amplitude VSR and annealing treatment have several negative effects on the fatigue life.

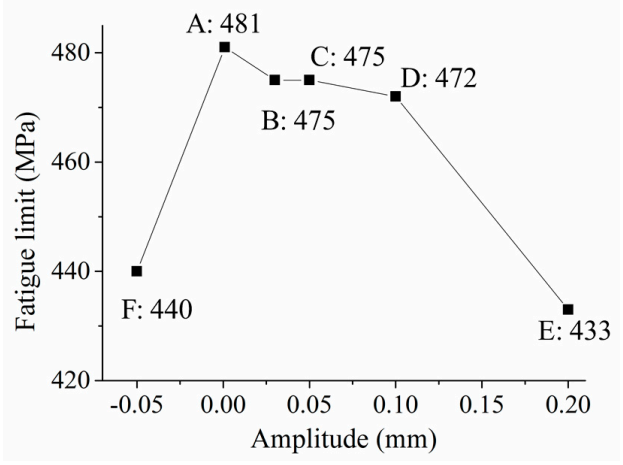

Figure 10. Fatigue limits under different amplitudes $(-0.05 \mathrm{~mm}$ amplitude stands for the annealing treatment). 


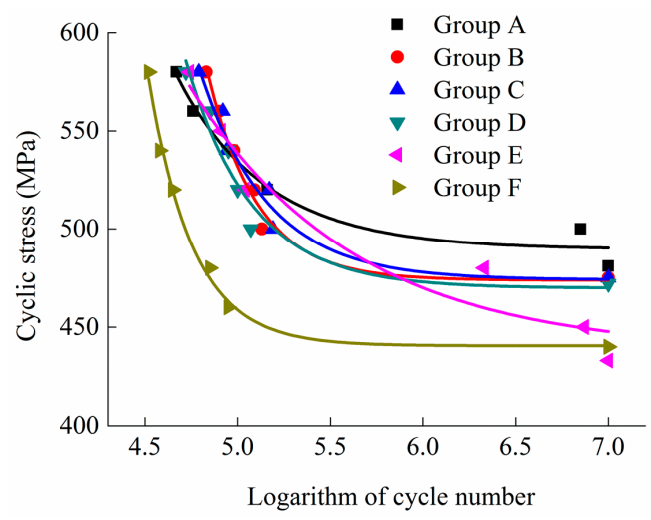

Figure 11. Cyclic stress amplitude-logarithm of cycle numbers (S-lgN) curves for Ti-6Al-4V titanium alloy.

Table 2. Fatigue limit and residual stress change after the VSR and annealing treatment.

\begin{tabular}{ccccccc}
\hline Results & Group A & Group B & Group C & Group D & Group E & Group F \\
\hline Fatigue limit (MPa) & 481 & 475 & 475 & 472 & 430 & 440 \\
Percentage change & $/$ & $-1.25 \%$ & $-1.25 \%$ & $-1.87 \%$ & $-10.60 \%$ & $-8.52 \%$ \\
Surface stress (MPa) & 217 & 86.7 & 108 & 34.1 & 21.3 & 5.91 \\
Percentage change & $/$ & $-60.05 \%$ & $-50.23 \%$ & $-84.29 \%$ & $-90.18 \%$ & $-97.28 \%$ \\
Average stress (MPa) & 13.55 & 1.22 & 4.47 & 3.43 & 4.24 & 8.15 \\
Percentage change & $/$ & $-90.99 \%$ & $-67.02 \%$ & $-74.68 \%$ & $-68.68 \%$ & $-39.87 \%$ \\
Dynamic stress (MPa) & $/$ & 8.68 & 14.43 & 28.76 & 57.22 & $/$ \\
\hline
\end{tabular}

When $\sigma_{\mathrm{d}}+\sigma_{\mathrm{r}}\left(\sigma_{\mathrm{r}}\right.$ is the residual stress, whereas $\sigma_{\mathrm{d}}$ is the dynamic stress in the VSR) is larger than the yield limit of the material in the local position, micro-plastic deformation occurs, and the internal residual stress is redistributed. The residual stress magnitude then decreases with the formation of a new stress equilibrium [42]. Therefore, micro-plastic deformation and stress redistribution that occur during the VSR process are the main reasons for the decrease and homogenization of residual stress.

The formation of fatigue damage can be divided into three stages: crack initiation, crack propagation, and instantaneous fracture. The crack is commonly generated in high stress areas under a cyclic load. The measured value of the strain gauge reflects the average strain in a certain area. Although the dynamic stress measured by the strain rosette is less than $60 \mathrm{MPa}$, the dynamic stress generated at the local position can be much larger than the measured value during the VSR process. The dynamic stress coupled with the initial residual stress can lead to local stress concentration, which then generates micro-cracks. This scenario explains the decrease in the fatigue life after VSR. Fewer cracks are produced after lower-amplitude VSR because lower dynamic stress is generated, and fewer stress concentration areas emerge during vibration. When the amplitude is less than a certain value, only a handful of cracks occur. Thus, the fatigue life slightly decreases. More cracks occur with the increases in the amplitude and dynamic stress. A larger decrease in the fatigue life is then observed after high-amplitude VSR.

Moreover, Figure 9a shows that the tensile stresses on the specimen surfaces in the original state, which are conducive to the initiation and propagation of fatigue cracks, are largely eliminated by VSR and annealing treatment. The decrease in the fatigue life demonstrates that the negative effects caused by the micro-crack generation during VSR are greater than the positive effects caused by the elimination of tensile stresses on the surface. If the surface residual stresses of the specimens in the original state is compressive, then a larger decrease in the fatigue life after VSR could be observed.

It should be noted that only five cyclic stress amplitudes of each state are selected to draw the $\mathrm{S}-\lg \mathrm{N}$ curve due to the high cost of time and raw material in experiments. The fatigue behavior can be 
better presented if more cyclic stress amplitudes are investigated. Besides, the results in this paper are basically effective on Ti-6Al-4V. The VSR effects on fatigue life vary with different metallic materials.

\section{Conclusions}

This study investigates the VSR effect on the fatigue life of Ti-6Al-4V. The dynamic stresses generated under different VSR amplitudes are initially measured, and then the relationship between the dynamic stress and vibration amplitude is obtained. VSRs with $0.03,0.05,0.1$, and $0.2 \mathrm{~mm}$ amplitude and annealing treatment under typical process parameters are conducted on five specimen groups. Another specimen group without any treatment is employed for comparison. The residual stresses of each group are measured to study the stress relieving effects. Finally, the fatigue limits and $\mathrm{S}-\operatorname{lgN}$ curves under different states are obtained by fatigue experiments. The following conclusions are drawn:

(1) The dynamic stress magnitude generated during the VSR process increases linearly with the amplitude increase. A higher amplitude is more conducive than the lower amplitude to the relief and homogenization of the residual stress of Ti-6Al-4V titanium alloy.

(2) VSR has a negative effect on the fatigue life of Ti-6Al-4V. The fatigue behavior decreased with the increase in the VSR vibration amplitude. When the VSR amplitude is less than $0.1 \mathrm{~mm}$, the decrease in the fatigue limit is less than $2 \%$. More than $50 \%$ of the surface residual stress and more than $67 \%$ of the average residual stress within $1 \mathrm{~mm}$ depth can be eliminated. The fatigue limit of the specimens treated by $0.2 \mathrm{~mm}$ amplitude VSR is decreased by $10.60 \%$. Although the stress relieving effect is better, high amplitude VSR will lead to the decrease of Ti-6Al-4V fatigue life due to the defects generated during vibration. Low amplitude VSR can effectively relieve the stress with little decrease in fatigue life.

(3) Annealing treatment also decreases the fatigue life. The fatigue limit of the specimens that underwent annealing treatment is decreased by $8.52 \%$. The S-lgN curve of the annealing treatment is generally lower than those of the VSRs with different amplitudes.

Acknowledgments: This work is supported by National Science and Technology Major Project (2014ZX04001011); State Key Laboratory of Virtual Reality Technology Independent Subject (BUAA-VR-16ZZ-07); Defense Industrial Technology Development Program (A0520110009); and Beijing Municipal Natural Science Foundation (3172021). The authors thank the referees of this paper for their valuable and very helpful comments.

Author Contributions: Han-Jun Gao, Yi-Du Zhang and Jing Song conceived and designed the experiments; Han-Jun Gao and Jing Song. performed the experiments; Han-Jun Gao and Qiong Wu analyzed the data; and Han-Jun Gao and Qiong Wu wrote the paper.

Conflicts of Interest: The authors declare no conflict of interest.

\section{References}

1. Barsoum, Z.; Barsoum, I. Residual stress effects on fatigue life of welded structures using LEFM. Eng. Fail. Anal. 2009, 16, 449-467. [CrossRef]

2. Schajer, G.S. Relaxation Methods for Measuring Residual Stresses: Techniques and Opportunities. Exp. Mech. 2010, 50, 1117-1127. [CrossRef]

3. Yeom, H.; Choi, B.; Seol, T.; Lee, M.; Jeon, Y. Very High Cycle Fatigue of Butt-Welded High-Strength Steel Plate. Metals 2017, 7, 103. [CrossRef]

4. Wu, Q.; Li, D.; Zhang, Y. Detecting Milling Deformation in 7075 Aluminum Alloy Aeronautical Monolithic Components Using the Quasi-Symmetric Machining Method. Metals 2016, 6, 80. [CrossRef]

5. Webster, G.A.; Ezeilo, A.N. Residual stress distributions and their influence on fatigue lifetimes. Int. J. Fatigue 2001, 23, 375-383. [CrossRef]

6. Cheng, X.; Fisher, J.W.; Prask, H.J.; Gnäupel-Herold, T.; Yen, B.T.; Roy, S. Residual stress modification by post-weld treatment and its beneficial effect on fatigue strength of welded structures. Int. J. Fatigue 2003, 25, 1259-1269. [CrossRef]

7. James, M.N.; Hughes, D.J.; Chen, Z.; Lombard, H.; Hattingh, D.G.; Asquith, D.; Yates, J.R.; Webster, P.J. Residual stresses and fatigue performance. Eng. Fail. Anal. 2007, 14, 384-395. [CrossRef] 
8. Sasahara, H. The effect on fatigue life of residual stress and surface hardness resulting from different cutting conditions of $0.45 \%$ C steel. Int. J. Mach. Tools Manuf. 2005, 45, 131-136. [CrossRef]

9. LaRue, J.E.; Daniewicz, S.R. Predicting the effect of residual stress on fatigue crack growth. Int. J. Fatigue 2007, 29, 508-515. [CrossRef]

10. Pouget, G.; Reynolds, A.P. Residual stress and microstructure effects on fatigue crack growth in AA2050 friction stir welds. Int. J. Fatigue 2008, 30, 463-472. [CrossRef]

11. Benedetti, M.; Fontanari, V.; Scardi, P.; Ricardo, C.L.A.; Bandini, M. Reverse bending fatigue of shot peened 7075-T651 aluminium alloy: The role of residual stress relaxation. Int. J. Fatigue 2009, 31, 1225-1236. [CrossRef]

12. Nikitin, I.; Scholtes, B.; Maier, H.J.; Altenberger, I. High temperature fatigue behavior and residual stress stability of laser-shock peened and deep rolled austenitic steel AISI 304. Scr. Mater. 2004, 50, 1345-1350. [CrossRef]

13. Bagherifard, S.; Slawik, S.; Fernández-Pariente, I.; Pauly, C.; Mücklich, F.; Guaglianoa, M. Nanoscale surface modification of AISI 316L stainless steel by severe shot peening. Mater. Des. 2016, 102, 68-77. [CrossRef]

14. Fernández-Pariente, I.; Bagherifard, S.; Guagliano, M.; Ghelichi, R. Fatigue behavior of nitrided and shot peened steel with artificial small surface defects. Eng. Fract. Mech. 2013, 103, 2-9. [CrossRef]

15. Zabeen, S.; Preuss, M.; Withers, P.J. Evolution of a laser shock peened residual stress field locally with foreign object damage and subsequent fatigue crack growth. Acta Mater. 2015, 83, 216-226. [CrossRef]

16. Yoichi, Y.; Yusuke, U.; Hiroshi, K.; Shinozaki, M. Fatigue life prediction of small notched Ti-6Al-4V specimens using critical distance. Eng. Fract. Mech. 2010, 77, 1439-1453.

17. Bourassa, P.L.; Yue, S.; Bobyn, J.D. The effect of heat treatment on the fatigue strength of microknurled Ti-6Al-4V. J. Biomed. Mater. Res. A 1997, 37, 291-300. [CrossRef]

18. Golden, P.J.; John, R.; Porter, W.J. Variability in Room Temperature Fatigue Life of Alpha + Beta Processed Ti-6Al-4V (Preprint). Int. J. Fatigue 2009, 31, 1764-1770. [CrossRef]

19. Zhang, Y.; Li, J.; Shi, C.-B.; Qi, Y.-F.; Zhu, Q.-T. Effect of Heat Treatment on the Microstructure and Mechanical Properties of Nitrogen-Alloyed High-Mn Austenitic Hot Work Die Steel. Metals 2017, 7, 94. [CrossRef]

20. Dawson, R.; Moffat, D.G. Vibratory Stress Relief: A Fundamental Study of Its Effectiveness. J. Eng. Mater. Technol. 1980, 102, 169-176. [CrossRef]

21. Walker, C.A.; Waddell, A.J.; Johnston, D.J. Vibratory stress relief-An investigation of the underlying processes. Proc. Inst. Mech. Eng. E-J. Process Mech. Eng. 1995, 209, 51-58. [CrossRef]

22. Sun, M.C.; Sun, Y.H.; Wang, R.K. The vibratory stress relief of a marine shafting of 35\# bar steel. Mater. Lett. 2004, 58, 299-303.

23. Sun, M.C.; Sun, Y.H.; Wang, R.K. Vibratory stress relieving of welded sheet steels of low alloy high strength steel. Mater. Lett. 2004, 58, 1396-1399. [CrossRef]

24. Wang, J.S.; Hsieh, C.C.; Lin, C.M.; Kuo, C.W.; Wu, W. Texture evolution and residual stress relaxation in a cold-rolled Al-Mg-Si-Cu alloy using vibratory stress relief technique. Metall. Mater. Trans. A Phys. Metall. Mater. Sci. 2013, 44, 806-818. [CrossRef]

25. Wang, J.S.; Hsieh, C.C.; Lai, H.H.; Kuo, C.W.; Wu, P.T.Y.; Wu, W. The relationships between residual stress relaxation and texture development in AZ31 Mg alloys via the vibratory stress relief technique. Mater. Charact. 2015, 99, 248-253. [CrossRef]

26. Rao, D.; Wang, D.; Chen, L.; Ni, C. The effectiveness evaluation of 314L stainless steel vibratory stress relief by dynamic stress. Int. J. Fatigue 2007, 29, 192-196. [CrossRef]

27. Kwofie, S. Plasticity model for simulation, description and evaluation of vibratory stress relief. Mater. Sci. Eng. A 2009, 516, 154-161. [CrossRef]

28. Lv, T.; Zhang, Y. A combined method of thermal and vibratory stress relief. J. Vibroeng. 2015, 17, $2837-2845$.

29. Vardanjani, M.J.; Ghayour, M.; Homami, R.M. Analysis of the Vibrational Stress Relief for Reducing the Residual Stresses Caused by Machining. Exp. Tech. 2016, 40, 705-713. [CrossRef]

30. Djuric, D.; Vallant, R.; Kerschbaumer, K.; Enzinger, N. Vibration stress relief treatment of welded high-strength martensitic steel. Weld. World 2011, 55, 86-93. [CrossRef]

31. Wozney, G.P.; Crawmer, G.R. An investigation of vibrational stress relief in steel. Weld. Res. Suppl. 1968, 23, 411-419.

32. Munsi, S.M.Y.; Waddell, J.; Walker, C. The Influence of Vibratory Treatment on the Fatigue Life of Welds: A Comparison with Thermal Stress Relief. Strain 2001, 37, 141-149. [CrossRef] 
33. Song, J.; Zhang, Y. Effect of vibratory stress relief on fatigue life of aluminum alloy 7075-T651. Adv. Mech. Eng. 2016, 8, 1-9. [CrossRef]

34. Wu, Q.; Zhang, Y.; Zhang, H. Dynamic characteristic analysis and experiment for integral impeller based on cyclic symmetry analysis method. Chin. J. Aeronaut. 2012, 25, 804-810. [CrossRef]

35. Baumeister, J.; Monno, M.; Goletti, M.; Mussi, V.; Weise, J. Dynamic Behavior of Hybrid APM (Advanced Pore Morphology Foam) and Aluminum Foam Filled Structures. Metals 2012, 2, 211-218. [CrossRef]

36. Gere, J.M.; Goodno, B.J. Mechanics of materials. In Mechanics of Materials; Van Nostrand Reinhold Co.: New York, NY, USA, 1972; pp. 211-291.

37. Fan, D. Heat treatment technology data manual. In Heat Treatment Technology Data Manual; China Machine Press: Beijing, China, 2000; pp. 497-499. (In Chinese)

38. Gao, Z.; Jiang, X.; Xiong, J.; Guo, G.; Gan, W.; Xia, Y.; Wang, S.; Zeng, B. Fatigue performance test design and data processing. In Fatigue Performance Test Design and Data Processing; Beihang University Press: Beijing, China, 1995. (In Chinese)

39. Chauvenet, W. A Manual of Spherical and Practical Astronomy. In A Manual of Spherical and Practical Astronomy; J. B. Lippincott \& Co.: Philadelphia, PA, USA, 1960.

40. Fu, W.E.; Cohen, P.H.; Ruud, C.O. Experimental investigation of the machining induced residual stress tensor under mechanical loading. J. Manuf. Process. 2009, 11, 88-96. [CrossRef]

41. Lia, B.; Jiang, X.; Yang, J.; Liang, Y.S. Effects of depth of cut on the redistribution of residual stress and distortion during the milling of thin-walled part. Thin-Walled Struct. 2015, 216, 223-233. [CrossRef]

42. Yildiz, K.; Eken, S.; Kaya, M.O. Simulation of vibration stress relief after welding based on FEM. Acta Metall. Sin. (Engl. Lett.) 2008, 21, 289-294.

(c) 2017 by the authors. Licensee MDPI, Basel, Switzerland. This article is an open access article distributed under the terms and conditions of the Creative Commons Attribution (CC BY) license (http:/ / creativecommons.org/licenses/by/4.0/). 